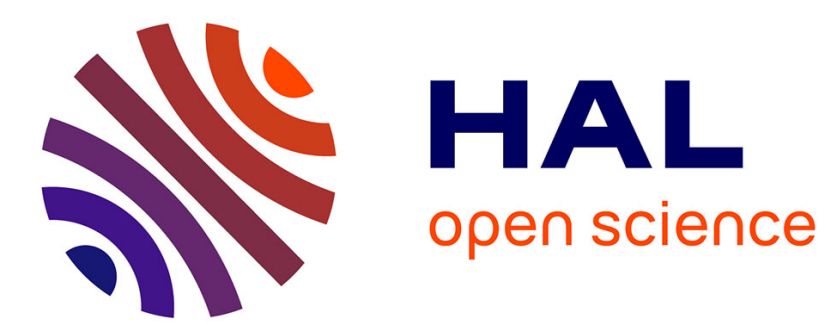

\title{
'Sufficiency Re-examined: A Capabilities Perspective on the assessment of Functional Adult Literacy'
}

\author{
Bryan Maddox, Lucio Esposito
}

\section{To cite this version:}

Bryan Maddox, Lucio Esposito. 'Sufficiency Re-examined: A Capabilities Perspective on the assessment of Functional Adult Literacy'. The Journal of Development Studies, 2011, pp.1. 10.1080/00220388.2010.509788 . hal-00676992

\section{HAL Id: hal-00676992 \\ https://hal.science/hal-00676992}

Submitted on 7 Mar 2012

HAL is a multi-disciplinary open access archive for the deposit and dissemination of scientific research documents, whether they are published or not. The documents may come from teaching and research institutions in France or abroad, or from public or private research centers.
L'archive ouverte pluridisciplinaire HAL, est destinée au dépôt et à la diffusion de documents scientifiques de niveau recherche, publiés ou non, émanant des établissements d'enseignement et de recherche français ou étrangers, des laboratoires publics ou privés. 


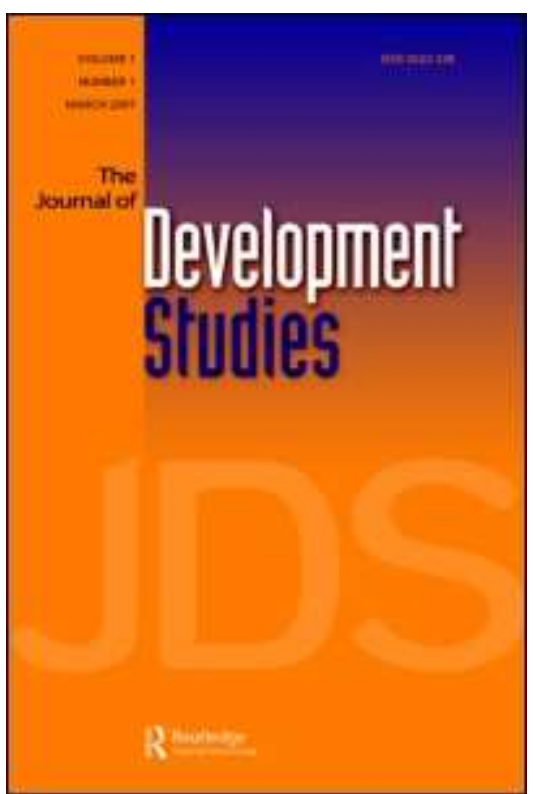

'Sufficiency Re-examined: A Capabilities Perspective on the assessment of Functional Adult Literacy'

\begin{tabular}{|r|l|}
\hline Journal: & Journal of Development Studies \\
\hline Manuscript ID: & FJDS-2009-Sep-0019.R1 \\
\hline Manuscript Type: & Original Manuscripts \\
\hline Keywords: & Adult literacy < Education, Literacy < Education \\
\hline \multicolumn{2}{|l}{} \\
\hline
\end{tabular}

\section{S scholarone \\ Manuscript Central}




\section{'Sufficiency Re-examined: A Capabilities Perspective on the assessment of Functional Adult Literacy'}

There is a consensus that dichotomous measures of literacy based on the 'literate and illiterate' distinction should be replaced by more nuanced and accurate forms of literacy assessment. The dichotomy, it is argued, over-simplifies the analysis, does not capture the range and plurality of literacy practices or the continua of abilities, and is a source of prejudice (Street 1995). The desire to abandon dichotomous measures is supported from contrasting disciplinary and institutional perspectives (Street 1995, Boudard and Jones 2003), and has strong support from development policy institutions (UNESCO 2008).

The search for successor approaches has however been less consensual. There is now intense debate about what represents good practice in literacy assessment (see Tierney, 2000), particularly on the subject of quantified literacy assessment in functional adult literacy (what we shall call literacy measurement). This debate is illustrated in the differences between psychometric and ethnographically informed approaches, which reveal a heavily contested conceptual terrain, including: the politics of literacy assessment regimes (Darville 1999, Hamilton 2001); the importance of social context; and the robustness of procedures for quantification and comparison (Street 1997, Levine 1998, Hamilton and Barton 2000, Blum, Goldstein and Guerin-pace 2001, Boudard and Jones 2003, Hamilton and Hiller, 2007). There are also pragmatic concerns about the practical and financial demands of literacy assessment (Wagner 2003). We can identify a series of demands arising from these debates that might reasonably be considered as requirements of functional adult literacy assessment. These include: flexibility (to incorporate diversity of literacies, practices and conceptions of literacy); rigour (to enable sufficient basis for comparison and statistical aggregation); autonomy (of groups and individuals in defining literacy requirements and conceptions of sufficiency); and transparency (to enable informed public debate on functional literacy needs and inequalities). 
At the heart of the debates over functional literacy however, are the ways in which concepts of sufficiency (adequacy) are constructed and measured. What does it mean to have 'enough' literacy? And Who decides? The decision to abandon dichotomous measures changes the way in which we answer those questions. In this paper we reexamine the notion of sufficiency that is at the heart of most definitions of functional adult literacy. Is the concept of minimal levels (thresholds) of literacy sufficiently robust and viable within notions of a continua of literacy practices and abilities? The debate over dichotomous measures and their successor also raises pragmatic questions about the purpose of literacy measurement projects; how reliable and comparable are literacy statistics? What do we make of correlations between literacy and other indicators of wellbeing (Iversen and Palmer-Jones, 2008)? It is our view that measures of functional literacy are intended to tell us whether people have achieved a minimum level or threshold of functioning (enough, adequate, sufficient) that is necessary for their daily life. They provide particularly important insights into educational achievement and inequality and are integral to multi-dimensional measures of poverty and human development (Maddox 2008).

\section{Fond Illusions? The measurement of functional literacy}

In 1982, Kenneth Levine published an article entitled 'Functional Literacy: Fond Illusions and False Economies'. Levine argued that the concept of functional literacy is vague, and characterised by 'an extreme elasticity of meaning' (p. 249). His paper provides a historical overview of the concept of functional literacy and its institutionalisation by UNESCO. The ambiguity of the term, he argues, supports an 'illusory consensus' about its content and benefits: 'In lieu of a comprehensive and coherent account of the role of literacy and illiteracy in society, we have nothing more than a jumble of ad hoc and largely mistaken assumptions about literacy's economic, social, and political dimensions' (p. 249-250). This is now familiar terrain to scholars of functional literacy.

Writing from a sociocultural perspective, Levine attempted to systematically identify and analyse these problems. He stressed the importance of subjective dimensions 
regarding literacy social identities and practice (p. 259). Further, as with Fisher's (1992) findings on income-based poverty lines, Levine notes the tendency for thresholds or minimum levels of adequacy to change over time (p. 260). He describes a threshold of functional literacy as: 'What is to count as survival, or adequate individual functioning within a community?' (p. 260), and goes on to note that the identification of such thresholds goes beyond questions of competence: 'The notion of survival, or adequate functioning, which it involves is thus irremediably a political and moral abstraction, placing the concept beyond the reach of any strictly empirical operationalizing procedure' (p. 260).

Levine had taken inspiration from Gray's (1956) classic definition of functional literacy, that a person is functionally literate 'when he has acquired the knowledge and skills in reading and writing which enable him to engage in all those activities in which literacy is normally assumed in his culture or group' (p. 24). The theoretical and methodological problems Levine identified remain important today. For example, commenting on Gray's definition he highlights the importance of contextual flexibility: 'This definition was intentionally relativistic, allowing for different thresholds of literacy in various societies...' (Levine, 1982, p. 253). Levine also offered some suggestions on how these problems might be resolved, including the idea of a 'basket of print mediated activities' that might reflect the diversity of cultural practice (p. 260). An idea that we shall return to later in the paper.

Levine's paper did not entirely resolve the challenges he had identified. The reason for this is perhaps the Achilles heel of the functional literacy concept, namely the desire to produce a single, unambiguous definition of functional literacy, and correspondingly standardised concept of adequacy. The diversity of social context and practice, and the existence of a 'multiplicity of literacies' (p. 264), seemed to render such standardisation and calibration unfeasible and inappropriate. ${ }^{\mathrm{i}}$ Instead, he argued for a process of identification and setting of thresholds that is idiosyncratic to the individual; that 'each individual is an expert arbiter of his or her own literacy needs' (p. 264). Levine's paper had attempted to formulate a theory of minimum thresholds that incorporated concepts of adequacy, and localised conceptions of practice. 
Levine's scepticism about the feasibility of such an approach was followed by similar arguments in New Literacy Studies, which was founded on criticism of 'great divide' theories of literacy, illiteracy and orality. The ethnographically informed New Literacy Studies described multiple forms of literacy use and literacies, rather than a single literacy (Street, 1995) and argued that the significance of literacy practices should be understood in terms of the social, cultural and institutional contexts in which they are embedded (Gee 2000). The dichotomy between literacy and illiteracy is usually viewed within the New Literacy Studies as an arbitrary reification revealing ethnocentric prejudice, theoretical naiveté, and institutional violence that privilege dominant forms of literacy over minority literacies (Collins and Blot 2003). The concept of 'illiteracy' is questioned, appearing in parenthesis as if constantly under erasure. Street (1995) illustrates this point, arguing that: 'It is not only meaningless intellectually to talk of 'the illiterate', it is also socially and culturally damaging' (p.19, see also Robinson-Pant, 2004).

A similar rejection of the dichotomous variable is evident in the quantitative assessment of functional adult literacy, though arguably, for quite different reasons (Boudard and Jones 2003). Many survey approaches consider the categories of literacy and illiteracy to be insufficiently nuanced to demarcate the range of competencies and practices that exist in most social contexts. The dichotomy is rejected, and replaced in most quantitative survey literature with the notion of multiple levels or 'thresholds'. This is illustrated by the OECD 'International Adult Literacy Survey' (IALS):

'The IALS no longer defines literacy in terms of an arbitrary standard of reading performance, distinguishing the few who completely fail the test (the "illiterates") from nearly all those growing up in OECD countries who reach a minimum threshold (those who are "literate”)' (OECD, 2000, p. X).

The UNESCO 'Literacy Assessment and Monitoring Programme' (LAMP) suggests and even more explicit rejection of the dichotomy:

'LAMP will provide a methodology to assess individual literacy levels over a range of competence to get away from the idea that one is either literate or illiterate' (UNESCO, 2004, p. 1) 
The intrinsic arbitrariness in setting thresholds has been discussed extensively in the poverty literature and there are obvious parallels. The arbitrary nature of any poverty line is an issue affecting both the use of a dichotomous index of poverty where an individual is simply classified as either 'poor' or 'non-poor', e.g. the headcount ratio, and the use of a polytomous index with different gradations of the 'poor'. This however, does not render all such analysis inappropriate. In an influential paper on poverty, Atkinson (1987, p. 750) warns the reader against an excessive discouragement resulting from the acknowledgement of the inherent arbitrariness resulting from the choice of a poverty line. He recalls that Sen "has stressed 'the danger of falling pray to a kind of nihilism [which] takes the form of noting, quite legitimately, a difficulty of some sort, and then constructing from it a picture of total disaster (1973, p. 78)". Rather than abandoning notions of thresholds and sufficiency, we therefore argue that what is required is sufficient transparency and rigour in their identification. We will explore these ideas further in relation to the Capabilities Approach. ${ }^{\text {ii }}$

\section{Literacy and Illiteracy: A Capabilities Perspective}

'illiteracy and innumeracy are forms of insecurity in themselves. Not to be able to read or write or count or communicate is itself a terrible deprivation. And if a person is thus reduced by illiteracy and innumeracy, we can not only see that the person is insecure to whom something terrible could happen, but more immediately, that to him or her, something terrible has actually happened' (Sen, 2003, p. 22). 
The Capabilities Approach opens up new avenues for the assessment of human wellbeing (Sen 1999, see also Anand, Santos and Smith, 2008, Comim, Qizilbash and Alkire 2008, Krishnakumar and Ballon, 2008). Within this influential approach, literacy is described as a core capability and functioning necessary for human wellbeing and a good life (Sen 1999, Nussbaum 2006). Amartya Sen argues that illiteracy is a 'focal feature' of capability deprivation and human insecurity (Sen, 1999). Illiteracy is viewed as a pervasive feature of capability deprivation and inequality, and literacy (particularly women's literacy) as a source of agency, autonomy and socio-economic mobility (Nussbaum, 1993, 2006, Sen, 1999, 2003, Maddox 2008).

Describing illiteracy as 'capability deprivation', it is necessary to theorise the nature of such disadvantage. From a capabilities perspective, illiteracy can be viewed in terms of its negative impacts in reducing people's ability to function effectively and to lead the kind of life they choose to value. The construction of illiteracy as social disadvantage has been challenged in the ethnographic literature. Street (1995) for example, argues that the Western concept of 'illiteracy' creates stigma, and that literacy campaigns '..have involved the construction of 'stigma' of illiteracy where many people had operated in the oral domain without feeling that it was a problem' (ibid, p. 14). From a capabilities perspective, this seems an implausible and inadequate explanation for literacy inequalities.

The Capabilities Approach however, provides theoretical insights that can inform new understandings of functional literacy. From a capabilities perspective, literacy can be understood not simply as cognitive abilities or competencies, but as a set of 'functionings' (as beings and doings), or the potential to function (Maddox 2008). The concept of literacy functionings is similar to that of 'literacy practices' in the ethnographic literature (see Street, 1993). Literacy functionings draw our attention to the social uses of literacy, and the production and embodiment of social identities. This aspect of literacy is widely recognised in the ethnographic literature (Bartlett and Holland, 2002, Bartlett, 2007).

\section{Thresholds and functionings}


'..my approach uses the idea of a threshold level of each capability, beneath which it is held that truly human functioning is not available to citizens; the social goal should be understood in terms of getting citizens above this capability threshold. (That would not be the only important social goal: in that sense I aim only to provide a partial and minimal account of social justice)' (Nussbaum, 2006, p. 71).

The 'threshold' operates as an important organising concept in the capabilities approach. This reflects the perceived importance of a core of 'basic' (Sen) or 'central' (Nussbaum) human capabilities that are required for wellbeing. It reflects a consequentialist concern with the achievement of functionings.

'The capabilities approach uses the idea of a threshold: for each important entitlement, there is an appropriate level beneath which it seems right to say that the relevant entitlement has not been secured' (Nussbaum, 2006, p. 291292).

Nussbaum's (2006) approach to minimum thresholds and adequacy is grounded in the concepts of human flourishing and the Marxian idea of a "truly human" life (p. 74). Sen shares similar philosophical commitments, but has a slightly different orientation to thresholds and adequacy. This is clearly influenced by liberal philosophy (e.g. Hume, Mill, Smith), and has resonance with wider debates on hunger, destitution, poor law and the moral economy. Sen recognises the multi-dimensional nature of human wellbeing, and although he is reluctant to specify a list of capabilities, his work draws our attention to a core of relatively few 'basic capabilities', that are necessary to avoid the worst kinds of human deprivation. The emphasis on adequacy or 'minimality' implies a 'bottom line' as critical points of demarcation, below which one locates core poverty and capability failure (Clark and Qizilbash, 2008).

Whether the concept of minimum threshold is informed by ideas on human flourishing or concerns with poverty and destitution, it raises a number of theoretical and procedural questions that have been discussed in recent literature. ${ }^{\text {iii }}$ One set of questions relates to the idea of 'arbitrariness', and the inherent (but necessary) 'vagueness' of multi-dimensional poverty measures. These questions were raised by Sen (1981): 
'The exercise of describing the predicament of the poor in terms of the prevailing standards of 'necessities' does of course, involve ambiguities, which are inherent in the concept of poverty; but ambiguous description isn't the same thing as prescription. Instead, the arbitrariness that is inescapable in choosing between permissible procedures and possible interpretations of prevailing standards requires recognition and appropriate treatment' (p. 23).

Sen appears to make a virtue out of an insight that might lead others to altogether dismiss measures of poverty. Criticising the concept of minimum threshold in the capabilities approach, Arneson (2000a) argues:

'One difficulty is how one nonarbitrarily sets the threshold level. Why here and not higher or lower? What we have is a smooth continuum of possible levels of overall capability for flourishing. Higher capability is always better than lower capability. But I do not see how any unique level (not even a broad thick line) can be picked out such that if a person has that level, she has enough' (p. 56).

The question of arbitrariness is central to Arneson's critique of thresholds. He is sceptical about the empirical basis of thresholds, and rejects their use as a basis for an ethics of social justice (Arneson 200a, b, 2006). Arneson (2000b) describes the capabilities approach to minimum thresholds as one of 'satisficing':

'The principle of justice that Nussbaum espouses asserts that the first priority of justice is to bring it about that every person gets a decent level of capability for each of the functionings that are needed for a genuinely good quality of life. For each person, what justice requires is not maximising any aspect of her condition, but satisficing: making sure that she has a sufficient level of capability' (p. 47)

Nussbaum's has criticised Arneson's representation of the capabilities approach as partial and inaccurate (Nussbaum, 2000b). Arneson's 'prioritarian' argument nevertheless provides a useful contrast to the focus of thresholds in the capabilities approach: 'The root idea of prioritarianism is that one ought as a matter of justice to aid the unfortunate, and the more badly off someone is, the more urgent is the moral imperative to aid' (2000a, p. 343). It is worthwhile to note that this prioritarian view can be still implemented should thresholds be identified: people below any chosen threshold would receive priority over people above it. 


\section{Arbitrariness and Identification}

As we have seen, one of the major challenges to the notion of a threshold between illiteracy and literacy is the question of arbitrariness (Sen, 1981). There is not a single literacy, but a plurality - multiple forms of literacy, literacy practices and functionings. This presents a challenge in terms of 'identification' (what counts as literacy). There is also the question of conceptualising and identifying literacy thresholds. Literacy and illiteracy, are not simply different amounts of the same thing, but distinct (if perhaps overlapping) social phenomena with their own characteristics. Rather than the smooth continuum, this requires us to identify points of transformation at which people's literacy functionings are adequate to enable flourishing and dignity, and avoid the forms of disadvantage associated with illiteracy.

In his paper 'On the arbitrariness and robustness of multi-dimensional poverty rankings', Qizilbash (2004) clarifies the conceptual distinction between 'horizontal' and 'vertical' vagueness, and their application in identification of the poor (ibid. p. 357). Horizontal vagueness indicates 'width', and the range of dimensions to be included, while vertical vagueness indicates depth, or the intensity of poverty (ibid. p. 
357). This clearly has relevance for literacy assessment. There is often insufficient discussion about the (horizontal) dimensions of literacy that are included in measures (i.e. which literacies and functionings) and the rational and procedures for their inclusion. ${ }^{\text {iv }}$ Literacy statistics based on conventional literacy rates have similar limitations to the 'headcount' measure in poverty measurement in that they fail to capture the vertical component and the severity of their poverty - 'It matters not at all [in the headcount measure] whether someone is just below the poverty line or very far from it, in acute misery and hunger' (Sen, 1981, p. 33). Even the more nuanced measure of 'effective literacy' popularised by the economists Basu and Foster (1998) neglect these horizontal and vertical dimensions. As the authors remark, the consideration of literacy as a dichotomous variable is a simplifying assumption enabling them to reduce the complexity of their model; in their own words, "This makes the usual assumption that individual literacy is a $0-1$ variable. Of course, the underlying literacy variable is likely to be continuous and even multivariate... We abstract from these potentially important considerations" (p. 1735).

The lack of access to vertical dimensions on the severity of illiteracy, or strength of literacy capabilities has limited the ability of literacy measures to account adequately for the size of literacy poverty gaps, the nature of inequality, and their distribution between different social groups. There is no equivalent measure of literacy that is able to tackle those challenges as the 'Foster, Greer and Thorbecke' (Foster et al., 1984) index does in poverty analysis. A 'vertical' dimension of literacy provides insights into the way that levels of literacy ability impact on people's capabilities. It might also support the identification of 'minimum thresholds'. As Qizilbash argues:

'In most exercises, where vertical vagueness is allowed for, there is some level of well-being above which, a person is definitely not poor, and another, below which a person is definitely poor' (Qizilbash, 2004, p. 357).

The literature on horizontal and vertical vagueness offers new possibilities for the measurement of literacy, and for the identification and analysis of minimum literacy thresholds. These developments involve methods for i) the identification of appropriate dimensions, and ii) appropriate procedures for setting minimum thresholds. A number of scholars made recourse to methodologies based on Fuzzy Set Theory to manage difficulties of arbitrariness and identification of poverty in 
situations of uni- and multi-dimensionality, inexactness, and contextual complexity (see Chiappero-Martinetti, 1994, Lelli, 2001, Qizilbash, 2004, and Clark and Qizilbash, 2008). This approach seems promising as there is no obvious cut-off point between illiteracy and literacy. Lelli (2001) notes that fuzzy sets allow for 'an element to partially to belong to a set', where.. 'the transition from membership to nonmembership takes place gradually rather than suddenly' (ibid. p. 6). Literacy and illiteracy can be viewed as overlapping 'fuzzy sets', where there are degrees of literacy and illiteracy around the threshold, and where each these sets have distinctive characteristics. People who fall below an agreed minimum threshold may still benefit from some lower level of literacy (Maddox, 2007). Others who are marginally above the threshold may still face some difficulties in functioning.

In theorising the concept of literacy thresholds, there are a number of alternative models that we can consider. The first argues that the concept is entirely arbitrary. This is what is suggested by Arneson's (2000a) idea of a smooth continuum, and by many ethnographic researchers who reject the concept of illiteracy, and view the term as an unwelcome imposition. As Street (1993) argues, drawing on the work of Besnier (1988), the notion of a continuum of literacy is problematic '..the concept of a 'continuum' is inadequate because spoken and written activities do not in fact line up along a continuum but differ from each other in a complex and multidimensional way' (Street, 1993, p. 4). Even if we impose a scale based on ideas of 'competence', this cannot fully predict people's literacy functionings, as they will be dependent on wider contextual factors. As Besnier (1988) argues, genre types such as a 'letter', vary considerably within social contexts, and have multiple sub-genres and registers (p. 731).

A second approach is to view the threshold as a point (a thick or thin line) that reflects qualitative transformations in people's ability to function. As Qizilbash (2004) suggests, even a thick line can be viewed as arbitrary. However, rather than suggesting a 'smooth continuum', it is compatible with the idea of the threshold representing points of discontinuity and change. The question that one must inevitably ask is - what type of literacy functioning one wishes to identify or promote? Qizilbash (2004), and Clark and Qizilbash (2008), for example, focus on the identification of an unambiguous 'bottom line', a 'critical minimal threshold' of core 
poverty. Nussbaum's threshold relates to human flourishing, while Gutmann's (1999) 'democratic threshold principle' argues that the appropriate threshold for literacy is not the economic orientation of many functional literacy programmes, but a higher threshold required for democratic citizenship: 'the democratic standard is consistent with the view that there is some absolute minimum of literacy below which no democratic society could be said to promote an adequate education to its citizens' (p. 139). Our attention is drawn then, not to some 'natural' point of demarcation, but for evidence of transitions in functioning related to particular social goals.

A somewhat different approach to thresholds is provided by the anthropologist Victor Turner (1969) in his work on liminality. The concept, based on the Latin, limen, (threshold), draws Van Gennep's work on rites of passage (Barnard and Spencer, 1996, p. 490). Turner's theory described ritual processes which involved processes of separation, liminality, and reaggregation into the social order. The liminal phase, he argued involved marginality and ambiguity, and a symbolic 'anti-structure in which normal social conventions seemed to be turned upside down:

'The attributes of liminality or liminal personae ("threshold people") are necessarily ambiguous, since this condition and these persons elude or slip through the network of classifications that normally locates states and positions in cultural space' (Turner,1969, p. 95).

This is clearly a quite different understanding of threshold to those discussed above. It draws our attention to a social space of liminality (a threshold space), in which transitions from illiteracy to literacy take place.

Turner's theory of thresholds draws our attention to the inherent ambiguity of literacy and illiteracy as social categories, and highlights their inter-subjective character. ${ }^{\mathrm{v}} \mathrm{His}$ theoretical insights also help us to analyse the collective and individual processes of transition associated with literacy acquisition. Adult literacy classes can be viewed as ritual spaces, where normal social conventions do not apply (women are centre stage, people make grand pronouncements about social commitments and development). This ritual process is particularly strong in national literacy campaigns, which often appear somewhat surreal in their portrayal of the social order. While this does provide opportunities for learning and change, the subsequent process of 'reaggregation' often 
results in people (particularly women) being unable to actually use literacy in their daily life (Puchner, 2003). The concept of 'literacy relapse' may therefore be more to do with social opportunities, than cognitive abilities.

\section{Subjective Measures and Hard Facts}

'For the person studying and measuring poverty, the conventions of society are matters of fact' (Sen, 1981, p. 17)

The process of identification of literacy functionings and thresholds involves important theoretical and procedural choices involving the status of local cultural perspectives. The principle of autonomy referred to above grants individuals and communities the agency to identify the dimensions of wellbeing. Indeed, in Sen's discussion of 'capability lists', he stresses the importance of 'public participation in what should be included and why' in order to avoid evaluation exercises 'completely divorced from the particular social reality that any particular society faces' (Sen, 2004, p. 77-78). Even Nussbaum, despite her criticism of relativism, gives considerable attention to the local interpretation of capabilities. This is illustrated in her discussion of Chen's work on adult literacy in Bangladesh, where processes of localisation are central to her argument (Nussbaum, 1993). While the capabilities approach entails strong normative themes (e.g. of universality), this recognition of the local, and cultural pluralism is a salient feature in the capabilities approach (Sen, 1999, Nussbaum, 2006 and Crocker, 2006).

The issue of the subjective and local is illustrated by Clark and Qizilbash (2008) in their paper on poverty evaluation in South Africa. They use participatory ranking to respond to problems of arbitrariness and in the identification of 'core poverty'. Similar participatory approaches have been developed in subjective studies of wellbeing (Gough and McGregor, 2007). Graff (1991) argued that the subjective nature of census measures does not undermine their reliability. This may in part relate to their vagueness of census specification. Even where subjective measures specify particular definitions of literacy, it is likely that people will apply their own interpretations based on local conventions. 
A number of recent papers have been critical of subjective measures of literacy, and question their use in literacy measurement (e.g. Schaffner 2005, Nath 2007). Schaffner (2005) uses demographic and health survey data (from Ethiopia and Nicaragua) to argue that subjective measures of literacy overestimate literacy rates. She creates a category of 'false rates' to indicate the difference between subjective rates, and the 'objective', test based measures: 'False rates are calculated as the percent of individuals with positive subjective literacy supports who failed the objective literacy test' (Schaffner, 2005, p. 655). However, Schaffner implies that the subjective rates are the source of error. The test based measures are viewed as being more accurate. This does not take into account the possibilities of error from normative judgements or procedural difficulties involved in a standardised literacy in diverse cultural contexts (see Blum, Goldstein and Guerin Pace 2001). Nor does it adequately recognise the value of subjective measures in providing localised understandings of literacy.

Nath (2007) also discusses differences between self-reported and test-based literacy survey data in Bangladesh. He views such ‘discrepancies' as illustrating 'underreporting' or more frequently 'over-reporting' in the self-assessment processes. '..people in general have a tendency to inflate the literacy data when they report it in the household survey' (Nath 2007, p. 130). His paper does not consider the possibility that the test itself, or the setting of their threshold may be the source of such discrepancy. Nath's data seem to show something else, which his paper does not recognise. In the analysis the percentage of 'under-reported' cases was highest within groups who had between 4-5 years of schooling, and was almost negligible with those who had either no schooling, or 11+ years of schooling; 'An inverse $U$ shape relationship was analysed against schooling of the respondents' (Nath, 2007, p. 127). A threshold theory of literacy helps to explain this finding and illustrates its intersubjective character. It appears that in Nath's Bangladesh data, 4-5 years of schooling locates an ambiguous threshold of literacy where many (24.8\%) of the respondents considered their functioning as adequate while the researchers begged to differ.

The International Adult Literacy Survey (2000) also discusses the 'problems' associated with subjective (self-reported) measures: 
'Many adults who score poorly in the literacy test do not themselves consider this to be a problem.. Nonetheless, the data.. point to the real limitation low levels of skills bring - regardless of whether these limits are acknowledged by those with low skills' (OECD, 2000, p. 53)

The stance of IALS and Schaffner (2005) on pluralism and subjectivity seems to be incompatible with the principles of the capabilities approach, as they privilege normative measures and standardisation as the basis of 'hard' facts, rather than understanding local meanings and practice. The relegation of subjective perspectives to 'soft' facts is a reflection of the institutional and epistemological politics involved.

'..hardness' is not located in the facts themselves, but in the community that agrees upon it, that is the community governing the politics of explanation.. The hardness of facts is an expression of social agreement rather than the quality of the facts themselves' (Hastrup, 1993, p. 734).

The preoccupation with objective 'hard facts' and standardisation as the foundation of comparative validity has been the source of much criticism (Hamilton and Barton, 2000 and Hamilton, 2001). Kanbur and Shaffer (2007) note the tendency for quantitative data to privilege 'brute data' and exclude 'private sensations' and 'intersubjective knowledge claims' (p. 186), and a bias toward 'standardisation, as a means of ensuring validity' (p. 192).

Hamilton (2001) argues the IALS approach neglects local and vernacular literacy practices (those informal practices most connected with every-day life) and is partial in its account of literacy:

'Testees can only respond in tightly scripted ways (or transgress by not responding) and they have no agency to define what literacy might mean to them. Adults' self assessments, although recorded are down graded in relation to the objectivity of the test' (p. 187).

As these arguments highlight, the imposition of technically derived assessment criteria is an unsatisfactory way to identify literacy thresholds. It privileges 'competence' over functioning, neglects the local and subjective, and constrains the scope of public deliberation.

\section{Capabilities and Functional Literacy Assessment}


In this final section we illustrate a methodological application of the Capabilities Approach in the assessment of functional literacy. In accordance with the principles informing the Capability Approach discussed above, we view people's literacy capabilities as a set of achieved literacy functionings among those that are valued by individuals or groups living in a certain social context.

The following process of quantification involves a series of steps. Initially, a set of valued literacy functionings has to be identified. The list can be derived in a number of ways, including participatory processes, public deliberation, and individual preferences. Then the quantification of literacy capabilities for an individual or group can be undertaken through the assessment of achieved and valued functionings. ${ }^{\mathrm{vi}}$

In the example below, suppose that the valued literacy functionings $f_{1}, f_{2}, f_{3}, f_{4}$ and $f_{5}$ have been identified. Anne has a literacy capability set that includes four achieved functionings $\left(\stackrel{v}{f}_{1}, f_{2}, f_{3}\right.$ and $\left.\stackrel{v}{f_{5}}\right)$, and one valued functioning that is not achieved $\left(\begin{array}{c}\times \\ f_{4}\end{array}\right)$. In the case of Joe, two of the valued functionings are achieved $\left(\stackrel{\vee}{f_{1}}\right.$ and $\left.\stackrel{v}{f_{3}}\right)$ and the literacy capability set is more restricted. We can attach, respectively, 1 or 0 to indicate whether the valued functioning is achieved or not:

$$
\begin{aligned}
& \begin{array}{ccccc}
\vee & \vee & \vee & \times & \vee \\
f_{1} & f_{2} & f_{3} & f_{4} & f_{5}
\end{array}
\end{aligned}
$$

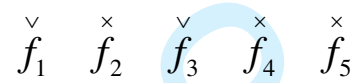

$$
\begin{aligned}
& \text { Anne: }\left\{\begin{array}{lllll}
1 & 1 & 1 & 0 & 1
\end{array}\right\} \quad \text { Joe: }\left\{\begin{array}{lllll}
1 & 0 & 0 & 1 & 0
\end{array}\right\}
\end{aligned}
$$

An additive approach is then able to offer the number (or proportion) of achieved valued functionings for each individual. More formally, let the vector $f_{i}=\left(f_{i, 1}, f_{i, 2}, \ldots, f_{i, m}\right)$ represent the state of achievement/failure for $m$ selected literacy functionings of individual $i$, with $f_{i, j}=1$ if individual $i$ achieves functioning $j$ and $f_{i, j}=0$ otherwise. The index $L_{i}=\frac{1}{m} \sum_{j=1}^{m} f_{i, j}$ would evaluate individual $i$ 's functional literacy as the proportion of achievements among a set of valued functionings - Anne 
would then score 0.8 and Joe 0.4 . This methodology reflects the conceptualisation of literacy functionings discussed above, and can be easily operationalised.

In our approach, whether a certain functioning belongs to the literacy capability set or not depends on the value attached to the practice and is independent of its complexity. The identified valued literacy functionings are not ranked in terms of their difficulty. It would be misleading to assume a priori that apparently 'easier' functionings are always achieved before those that are more complex. ${ }^{\text {vii }}$ While functionings may be characterised by different levels of complexity, there may not be an obvious hierarchy of practice. The achievement of literacy functionings is not only dependent on their apparent complexity, but on a range of wider factors relating to social context, practices and their value. Furthermore, the recognition of interpersonal heterogeneity is a salient feature of the Capability Approach. The same literacy functioning can be straightforward to some and arduous for others. These considerations help to recognise the potential of people to develop diverse literacy capability sets at a similar level of 'competency'.

In contrast with the notion of difficulty, the Capability Approach suggests a hierarchy of functionings based on values attached to them (Sen, 2004). In our approach this can be accommodated by attributing weights $\alpha_{j}$ to each functioning, so that the researcher can give more importance to some of them - for example, to those that are highly valued by an individual or community. The index would now be a weighted sum $L_{i}^{\alpha}=\frac{1}{m} \sum_{j=1}^{m} \alpha_{j} f_{i, j}$, which for Anne and Joe would become, respectively, $L_{\text {Amme }}^{\alpha}=\frac{\left(\alpha_{1}+\alpha_{2}+\alpha_{3}+0+\alpha_{5}\right)}{5}$ and $L_{J o e}^{\alpha}=\frac{\left(\alpha_{1}+0+0+\alpha_{4}+0\right)}{5}$. Note that the use of weights may result in Joe scoring higher than Anne if functioning $f_{4}$ is particularly highly valued.

At the aggregate level, a matrix can be used to depict the overall distribution of achievements/failures of functionings across individuals: 


$$
\begin{aligned}
& n \text { individuals } \\
& \begin{array}{llll}
f_{1,1} & f_{1,2} & \cdots & f_{1, m}
\end{array} \\
& \mathrm{X}=\begin{array}{ccccc}
f_{2,1} & f_{2,2} & \cdots & f_{2, m} & m \text { dimensions } \\
\ldots & \ldots & \ldots & &
\end{array} \\
& \begin{array}{llll}
f_{n, 1} & f_{n, 2} & \ldots & f_{n, m}
\end{array}
\end{aligned}
$$

Each row represents the literacy situation of an individual, while each column shows the achievement or failure of a specific functioning across individuals. The quantification of the overall literacy capabilities of a group or society of $n$ individuals requires to aggregate across functionings and across individuals through the doubly additive index $L=\frac{1}{m} \sum_{i=1}^{n} \sum_{j=1}^{m} f_{i, j}-$ or $L^{\alpha}=\frac{1}{m} \sum_{i=1}^{n} \sum_{j=1}^{m} \alpha_{j} f_{i, j}$ if weights are taken into account. When social groups of different size are compared it may be useful to look at those figures normalised by $n$.

This approach enables comparisons across diverse locations and over time based on people's capacity to achieve their valued functionings, rather than the actual content of the functionings. I.e. like the 'basket of goods' used to estimate poverty lines, the inclusion of different items across contexts does not invalidate comparison. An alternative perspective is therefore offered to psychometric literacy assessment methodologies (such as IALS), where international comparisons rely on the standardisation of test items and notions of 'universal competencies' (see Boudard and Jones 2003). This standardisation has been the subject of much criticism becasue of its neglect of cultural differences in literacy practice (Blum et al. 2001, Hamilton 2001).

Finally we come to the issue of sufficiency thresholds. We see two intriguing options within our approach. The threshold may be seen as the achievement either of a minimum number of valued functionings or of a set of 'core' functionings that are deemed indispensable in a certain social context. The severity of the inadequacy of a person's capability set would correspond directly to the number of 'missing' functionings for the reaching of the threshold. Consider the exemplification presented above. If the minimum literacy threshold is conceptualised as the achievement of at 
least two of $f_{1}-f_{5}$ then Joe's literacy capability would satisfy such a requirement. In case that, instead, the threshold is thought of as the achievement of both specific functionings $f_{1}$ and $f_{2}$ then Joe's literacy capability set would be insufficient. The severity of this failure would be larger if Joe were to achieve functionings $f_{3}$ and $f_{4}$ rather than functionings $f_{l}$ and $f_{4}$. Following both specifications Anne would reach the literacy threshold.

\section{Conclusions}

There is a broad consensus on the need to replace the conventional dichotomous measure of functional literacy. The search for an acceptable successor raises conceptual and methodological debates and difficulties that are not yet adequately resolved. The characteristics of a successor approach include multiple, and at times competing demands (e.g. flexibility, rigour, autonomy and transparency). These characteristics are shaped by the contrasting politics and objectives of 'measurement regimes' (Hamilton 2001). This paper has argued that functional literacy assessment is guided by two questions - What does it mean to have 'enough' literacy? And who decides? Our answer to both questions is informed by the Capabilities Approach. We have argued that the projects and procedures of measuring functional adult literacy should determine whether people have ability to achieve the literacy functionings that they (or the society they live in) value. As such, statistics on functional literacy play an important role in the measurement of human development and inequality.

Functional literacy assessment is concerned with questions of sufficiency. This remains the case whether one uses self-reported measures or those of 'direct assessment', whether one conceptualises literacy as a dichotomous or polytomous phenomenon. To entirely reject the notion of sufficiency and minimum thresholds can be described following Sen (1981) as a 'robust example of misplaced sophistication' (p14). The ways that they are measured, the location and content of minimum thresholds, and the significance of adult literacy statistics produced should be the subject of transparent public debate and deliberation. 
While distinctions between literacy and illiteracy might be considered to be arbitrary, in that they are based on value judgements, they can, as the paper has demonstrated, be rigorously identified and produced. Nevertheless, the significance of attaining a 'minimum threshold' may be over-stated. Arneson's critique of 'satisficing' suggests that while a threshold of adequate literacy can be identified, 'more literacy' (as levels or the number of achieved functionings) continues to improve people's chances of human flourishing and a dignified life. Similarly, improvements of people's literacy capabilities below an agreed threshold may also contribute to their quality of life. This has implications for policies of primary schooling, adult literacy and non-formal education, which may for various reasons fail to help people to reach desired thresholds, but make valuable contributions to human development.

\section{NOTES}

i Levine's (1982) rejection of 'lists' of texts and functions to identify a threshold of functional literacy has clear parallels with the debate over selection of definitive lists of functionings and capabilities in the work of Sen (2004).

ii In this paper we use the term Capabilities Approach (i.e. plural capabilities). This has become the established term in the literature (e.g. Nussbaum 2006). When referring to Sen's work (Sen 1985, 1999) we use the term Capability Approach, reflecting his terminology.

iii These distinctions between underlying principles that inform concepts of minimality can be overstated. Qizilbash (2002), notes 'shared values' in the literature on capabilities, prudential values and basic goods, and some convergence of approaches.

iv The selection of dimensions of literacy, and the levels at which thresholds are set rarely involve transparent and democratic processes. This reflects the historical and institutional politics involved. The capabilities approach offers and important opportunity to democratise such procedures, as it suggests that such questions are a legitimate and necessary topic for public deliberation, rather than the realm of technocratic and 'expert' decisions.

${ }^{v}$ The concept of threshold space might usefully be applied in analysis of distribution of literacy in developing countries, and shape educational policy. Mapping the vertical dimension of literacy would help us to profile the number of people who operate in this threshold area, and those who are either unambiguously literate or illiterate.

vi It is worth noting that under this approach it is possible to identify and assess both sets of valued functionings deriving from consensual processes and idiosyncratic sets deriving from individual preferences.

vii The issue of difficulty is more complex that one might initially expect. It is the subject of much debate and certainly merits further investigation (e.g. Blum et al. 2001). 


\section{REFERENCES}

ANAND, P., SANTOS, C. \& SMITH R. (2008). The Measurement of Capabilities. In K. Basu and R. Kanbur (Eds), Festschrift for Amartya Sen, (pp. 283-310). Oxford University Press, Oxford.

ARNESON, R. (2000a). Luck Egalitarianism and Prioritarianism. Ethics, 110, 339349.

ARNESON, R. (2000b). Perfectionism and Politics. Ethics, 111, 37-63.

ARNESON, R. (2006). Distributive Justice and Basic Capability Equality: 'Good Enough' is not good enough. In Capabilities Equality: Basic Issues and Problems, (pp. 17-43).Routledge, London and New York.

ATKINSON, A. B. (1987). On the measurement of poverty. Econometrica, 4, 749764.

BARNARD, A. \& SPENCER, J. (1996). Encyclopaedia of Social and Cultural Anthropology. Routledge, London.

BARTLETT, L. (2007). To Seem and To Feel: Situated Identities and Literacy Practices. Teachers College Record, 109, 1, 51-69.

BARTLETT, L., \& HOLLAND, D. (2002). Theorizing the Space of Literacy Practices. Ways of Knowing, 2, 1, 10-22.

BARTON, D., \& HAMILTON, M. (1998). Local Literacies: Reading and writing in one community, London, Routledge.

BARTON, D., HAMILTON, M., \& IVANIC, R. (Eds), (2000). Situated Literacies: Reading and Writing in Context. Routledge, London.

BASU, K., \& FOSTER, J. (1998). On Measuring Literacy. Economic Journal, 108, 1733-1749.

BASU, K., NARAYAN, A., \& RAVALLION, M. (2002). Is literacy shared within households? Theory and evidence from Bangladesh. Labour Economics, 8, 649-665. Registers. Language, 64, 4, 707-736.

BLUM, A., GOLDSTEIN, H.\& GUERIN-PACE, F. (2001) 'International Adult Literacy Survey (IALS): an analysis of international comparisons of adult literacy', Assessment in Education, Vol. 8, No. 2, pp225-246. 
BOUDARD, E. \& JONES, S. (2003). The IALS approach to defining and measuring literacy skills. International Journal of Educational Research, 39, 191-204.

BOURGUIGNON, F. \& FIELDS, G. (1997). Discontinuous losses from poverty, generalized $P_{\alpha}$ curves, and optimal transfers to the poor. Journal of Public Economics, 63, 155-175.

CHIAPPERO-MARTINETTI, E. (1994). A New Approach to Evaluation of Wellbeing and Poverty by Fuzzy Set Theory. Giornale Degli Economisti e Annali di Economia, 53, 367-388.

CLARK, D., \& QIZILBASH, M. (2008). Core Poverty, Vagueness and Adaptation: A New Methodology and Some Results for South Africa. Journal of Development Studies, 44, 4, 519 - 544.

COLLINS, J. \& BLOT, R. (2003). Literacy and Literacies: Texts, Power and Identity. Cambridge, Cambridge University Press.

COMIM, F., QIZILBASH, M. \& ALKIRE, S. (Eds.) (2008) The Capability Approach: Concepts, Measures and Applications. Cambridge, Cambridge University Press.

CROCKER, D. (2006). Sen and Deliberative Democracy. In A. Kaufman (Ed.) Capabilities Equality: Basic Issues and Problems, (pp. 44-70). Routledge, London and New York.

DARVILLE, R. (1999), Knowledges of Adult Literacy: Surveying for

Competitiveness, International Journal of Educational Development 19, 273-85.

MENZES DE SOUZA, L.M (nd) 'The Cultural Logics of Indigenous Perspectivism and Predation'

DASGUPTA, P. (1993). An inquiry into destitution and wellbeing. Clarendon Press, Oxford.

DREZE, J., \& SEN, A.K. (2002). India: Social Participation and Development, Oxford University Press, Delhi and Oxford.

FINNEGAN, R. (1988). Literacy and Orality. Basil Blackwell, Oxford.

FISHER, G. M. (1992). The Development and History of the Poverty Thresholds.

Social Security Bulletin, 55, 4, 1992, 3-14.

FOSTER, J., GREER, J., \& THORBECKE, E. (1984). A Class of Decomposable Poverty Measures. Econometrica, 52, 761-765.

GASPER, D. (2002). Is Sen's Capability Approach an Adequate Basis for Considering Human Development?. Review of Political Economy. 14, 4, 435-461. 
GEE, J. (2000). The New Literacy Studies: from "socially situated" to the work of the social. In Barton, D, Hamilton, M., and Ivanic, R. (Eds.) Situated Literacies: Reading and Writing in Context (pp. 180-196), Routledge, London.

GIBSON, J. (2001). Literacy and Intrahousehold externalities. World Development, $29,1,155-166$.

GOUGH, I., \& MCGREGOR, A. (Eds), (2007). Wellbeing in Developing Countries: From Theory to Research'. Cambridge University Press, Cambridge.

GRAFF, H.J. (1991). The Literacy Myth: Cultural Integration and Social Structure in the Nineteenth Century. New Brunswick, NJ: Transaction Publishers.

GRAY, W.S. (1956). The Teaching of Reading and Writing: an International Survey. Unesco, Paris and Evans Brothers, London.

GRUSKY, D., \& KANBUR, R. (2006). Introduction: The conceptual foundations of poverty and Inequality Measurement. In D. Grusky and R. Kanbur (Eds.) Poverty and Inequality. Stanford University Press.

GUTMANN, A. (1999). Democratic Education. Princeton University Press, New Jersey.

GOODY, J. (1986). The Logic of Writing and the Organisation of Society, Cambridge, Cambridge University Press.

GOODY, J. (2000). The Power of the Written Tradition, Washington, Smithsonian.

GRAFF, H. (1991). The Literacy Myth: Cultural Integration and Social Structure in the Nineteenth Century. New Jersey.

HALVERSTON, J. (1992). Goody and the Implosion of the Literacy Thesis. Man, 27, 301-317.

HAMILTON, M. (2001). Privileged Literacies: Policy, Institutional Process and the life of the IALS. Language and Education, 15, 178-196.

HAMILTON, M., \& BARTON, D. (2000). The International Adult Literacy Survey: What does it really measure? International Journal of Education, 46, 5, 377-389.

HAMILTON, M., \& HILLIER, Y. (2007). Deliberative policy analysis: adult literacy assessment and the politics of change. Journal of Educational Policy, 22, 5, 573-594.

HASTRUP, K. (1993). Hunger and the Harness of Facts. Man, 28, 727-739.

IVERSEN, V. and PALMER-JONES, R. (2008) 'Literacy Sharing, Associative Mating of What? Labour Market Advantages and Proximate Illiteracy Revisited'. Journal of Development Studies. Vol. 44, No. 6. pp797-838. 
KANBUR, R., \& SHAFFER, P. (2007). Epistemology, Normative Theory and Poverty Analysis: Implications for Q-Squared in Practice. World Development, 35, 2, 183-196.

KELL, C. (1996). Literacy practices in an informal settlement in the Cape Peninsula. In M. Prinsloo, M. and M. Breier (Eds.) The Social Uses of Literacy. John Benjamins and Sached Books, Amsterdam and Cape Town.

KRISHNAKUMAR, J. \& BALLON, P. (2008). Estimating Basic Capabilities: A Structional Equation Model Applied to Bolivia. World Development. 36, 992-1010.

LELLI, S. (2001). Factor Analysis VS. Fuzzy Sets Theory: Assessing the Influence of Different Techniques on Sen's Functioning Approach. Discussions Paper Series 01.21, Department of Economics, Catholic University of Leuven

LEVINE, K. (1982). Functional Literacy: Fond Illusions and False Economies. Harvard Educational Review, 52, 3, 249-266.

MADDOX, B. (2007). What can ethnographic approaches tell us about the consequences of literacy? Comparative Education, 43, 2, 253-272.

MADDOX, B. (2008). What good is literacy? Insights and Implications of the Capabilities Approach. Journal of Human Development, 9, 2, 185-206.

MALAN, L. (1996). Literacy mediation and social identity in Newtown, Eastern Cape. In. M. Prinsloo \& M. Breier (Eds.). The Social Uses of Literacy. Amsterdam, and Cape Town. John Benjamins and Sached Books.

NATH, S. R. (2007). Self-Reporting and Test Discrepancy: Evidence from a National Literacy Survey in Bangladesh. International Review of Education, 53, 2, 119-134

NUSSBAUM, M. (1993). Women and Human Development: The Capabilities Approach. Cambridge University Press, Cambridge.

NUSSBAUM, M. (2000a). Women's Capabilities and Social Justice. Journal of Human Development, 1, 2, 219-246.

NUSSBAUM, M. (2000b). Aristotle, Politics and Human Capabilities: A response to Antony, Areneson, Charlesworth and Mulgan. Ethics, 111, 102-140.

NUSSBAUM, M. (2003). Women's education: A global challenge. Signs: Journal of Women in Culture and Society, 29, 2, 325-355.

NUSSBAUM, M. (2006). Frontiers of Justice, Belknap Harvard.

OECD (2000). Literacy in the Information Age. Final Report of the International Adult Literacy Survey. Paris, OECD. 
PARIS, S. (2005). Reinterpreting the development of reading skills. Reading Research Quarterly, 40, 2, 184-202.

PUCHNER, L. (2003). Women and literacy in rural Mali: a study of the socioeconomic impact of participating in literacy programs in four villages. International Journal of Educational Development, 23, 439-458.

QIZILBASH, M. (2002). Development, Common Foes and Shared Values. Review of Political Economy, 14, 4, 463-479.

QIZILBASH, M. (2004). On the Arbitrariness and Robustness of Multi-Dimensional Poverty Rankings. Journal of Human Development, 5, 3, 355-375.

ROBINSON-PANT, A. (2004). The "illiterate woman": Challenging approaches to researching women's literacy. In Robinson-Pant (Ed.) Women, Literacy and Development: Alternative Perspectives (pp. 15-34). London, Routledge.

SCHAFFNER, J. (2005). Subjective and objective measures of literacy: Implications for current results oriented development initiatives. International Journal of Educational Development, 25, 652-657.

SEN, A. K. (1973). On Economic Inequality. Clarendon Press, Oxford.

SEN, A. K. (1981). Poverty and Famines: An Essay on Entitlement and Deprivation. Clarendon Press, Oxford.

SEN, A. K. (1985). Commodities and Capabilities. Amsterdam, North-Holland.

SEN, A.K. (1990). Gender and Cooperative Conflicts. In I.Tinker (Ed.) Persistent Inequalities: Women and World Development (pp. 123-149). Oxford University Press, Oxford.

SEN, A.K. (1993). Capability and Wellbeing. In M. Nussbaum \& A. K. Sen. (Eds.) The Quality of Life (pp. 30-53). Clarendon Press, Oxford.

SEN, A.K. (1999). Development as Freedom. New Delhi, Oxford University Press.

SEN, A.K. (2003). Reflections on Literacy. In C. Robinson (Ed.) Literacy as Freedom. Unesco, Paris.

SEN, A.K. (2004). Dialogue: Capabilities, Lists and Public Reason: Continuing a Conversartion. Feminist Economics, 10, 3, 77-80.

SMITH, A. (1776). An Enquiry into the Nature and Causes of the Wealth of Nations. London, Everyman Edition.

STREET, B. (1984). Literacy in Theory and Practice. Cambridge, Cambridge University Press. 
STREET, B (Ed.). (1993) Cross-Cultural Approaches to Literacy. Cambridge, Cambridge University Press.

STREET, B. (1995). Social Literacies: Critical Perspectives on Development, Ethnography and Education. London, Longman.

STREET, B (1997) Literacy, Economy and Society: A Review. Working Papers on Literacy 1, 7-16. Centre for Literacy. Montreal.

SUBRAMANIAN, S. (2004). Measuring Literacy: Some extensions of the BasuFoster Framework. Journal of Development Economic, 73, 453-464.

TIERNEY, et al. (2000). 'How will literacy be assessed in the next millennium?', Reading Research Quarterly, Vol 35, No 2. pp 244-250.

THOMPSON, E.P. (1993). Customs in Common. Penguin London.

TURNER, V. (1969). The Ritual Process: Structure and Anti-Structure. Chicago: Aldine Publishing Co.

UNESCO. (2004). The Literacy Assessment and Monitoring Programme (LAMP). Unesco Institute of Statistics (UIS), Update, Nov. 2004.

UNESCO. (2005). Literacy for Life: The Education for All Global Monitoring Report. UNESCO, Paris.

UNESCO (2008) The Global Literacy Challenge. UNESCO Paris.

WAGNER, D. (2003). Smaller, quicker, cheaper: alternative strategies for literacy assessment in the UN Literacy Decade. International Journal of Educational Research, 39, 293-309. 